From the prognostic point of view the test is of very limited use, particularly in female cases. Regarding increased positivity in the test as a sign of an increased attempt at immunisation, and, therefore, as tending towards cure, I was at first hopeful that by means of a series of tests at suitable intervals it would be possible to prognose cure, or at least to determine whether a patient was making progress or otherwise. But I soon found that series of repeat tests on the same individuals showed remarkable fluctuations from positive to negative, and vice versa, without any apparent ayreement with the clinical condition at the same periods. This fluctuation is, in my experience, much more marked among women than men. And it makes it practically impossible to publish the results without quoting every case in extenso. I spent many weary hours wrestling with this problem, and as the result I venture to suggest an explanation which I readily admit may not be completely satisfactory and may not account for all similar cases. I put it forward for what it is worth in the hope of eliciting the views of others who have done many repeat tests on the same cases. Several of my cases were tested seven, eight, and even nine times.

The fact that struck me was that many cases of sone duration gave a negative, or at most a doubtful, reaction when both clinically and bacteriologically they showed active infection. Such a result as this frequently occurred : "Pus from cervix and urethra; films from both positive; test $-\ldots$ - Now this was too frequent to be explained by technical error. Moreover, it happened in cases which had previously given a positive reaction. It must, therefore, be due to absence of stimulation to antibody formation. Antibody formation takes place at some distance from the local site of infection, probably largely in the bone marrow. Whatever the antigen stimulating it, this must be carried by the blood to the antibody forming tissues. Some absorption from the local site must thus take place. In an open situation, such as the female urethra and the patulous cervix of gonorrhoa, there is little opportunity for absorption. Phagocytosis is here the normal method of resistance to the infecting organism. The pus formed has a free vent and is carried away.

This led me to examine more carefully the clinical records of those cases showing a positive reaction sandwiched between negatives or doubtfuls, and I found a considerable number of these showed closed-in foci, abseesses in Bartholin's glands being fairly common. Such a case as the following will explain what I mean :-

413. An old case.

June 24th : ++- . Urethra positive; cervix signs of old gleet.

August 20th : No test. Bartholin abscess, gonococc found in pus. Bartholin glands dissected out on Sept 8th.

Oct. 12th : ---

Oct. 30th: No test. Bartholins full of pus again (no note as to gonococci being found this time).

Nov. 27th: $\pm-\cdots$ Bartholins healed. Clinically negative.

Dec. 30th : +++ . Looks quite negative clinically.

Feb. 1st: - - - Clinically negative.

March 8th : $\doteq--$. (Regarded as a negative test.) Clinically negative. Discharged.

I suggest, as the explanation of this series, that there was originally a dammed-up focus in the Bartholin's glands from which antigenic absorption was taking place. The operation in September broke down the dam temporarily; a free outlet was allowed to the disintegrated products and antibody production ceased. The operation being incomplete, the dam was rebuilt (as shown by the note of Oct. 30th), and fresh absorption occurred, resulting in a rising reaction, culminating in December, and falling later as the condition proceeded to cure. I admit that few of the cases I tested are as apparently easy to interpret as this, and there are a number giving strong - positives where no mention is made of any obvious focus. None the less. there are a considerable number of cases of a similar character to the fore- going in which there are notes of "Bartholins enlarged,", "Bartholin abscess." "Skene's abscess,", "Tubes," and the like; and I think it is probable that if this view had been in the clinician's mind he would have found similar indications in other cases. This would also, I think, explain the more frequent occurrence of strong positive reactions in men than in women. Anatomically, men have more opportunity of hiding away the gonococcus than women.

But if this view be correct certain consequences follow. First, that a positive reaction is, from the prognostic point of view, far less evidence of an attempt at cure than evidence of an active, it may be hidden, shut off focus. I think it is very doubtful if antibody, in the sense of complement-fixing body, plays any considerable part in the cure of yonorrhoea. Secondly, that antibody formation-so far as our present tests can detect-soon ceases after a free outlet for the gonococcus and its products is established; that, in fact, antibody formation is proportionate to the amount of stimulus reaching the antibody forming tissues, or in other words, to the absorption by the blood of autolytic products. If this be the case, then no number of negative tests will ever serve as a test of cure. A strong positive reaction is of immense value as indicating a focus, perhaps not clinically obvious; but it would seem that the pronouncement of cure must remain in the clinician's observations. - I am, Sir, yours faithfully,

$$
\text { A. H. PRIEstuey, }
$$

Public Health Department, University of

$$
\text { Assistant }
$$

Birmingham, June 11th, 1922 .

\section{DIATHERMY IN SURGICAL PRACTICE.}

To the Editor of THE LANCET.

SIR,-I am afraid I must disclaim responsibility for the remarks attributed to me in the discussion on Diathermy in Surgical Practice which was reported in your issue of June 17th. I was an interested listener to the opening speeches at the meeting, but I was obliged to leave early, and so had no opportunity for speaking myself. Perhaps I may be allowed to put down here what I would have said if $I$ had been able to stay long enough.

In the first place, I wish to endorse what was said by Mr. Douglas Harmer in connexion with carcinoma of the tongue and mouth. I believe diathermy to be far the most hopeful treatment in all cases of carcinoma in the mouth, whether they be amenable to complete excision or not; and I have used this method entirely for the last 18 months with much better results than I ever obtained with the knife alone. I have not yet had any case of secondary hæmorrhage, but at the same time $I$ think it is advisable to tie the lingual artery in cases of carcinoma of the tongue, because I believe that starvation of the growth by curtailing its blood-supply is a very helpful factor in preventing recurrence. I have several times removed enlarged glands from the neck at the same time as I have used the cautery with no harmful result, and I can see no reason for deferring the operation on the glands to a later date. For rodent ulcers and epitheliomata of the skin, again, I consider that diathermy gives much better results than simple excision, and I now only excise very small early rodent ulcers which are situated on loose skin and can easily be removed without the risk of an inconvenient or unsightly scar. Where the base of the growth is bound down to deep structures the scar left by diathermy is frequently hardly noticeable, and, moreover, the healing in these cases is remarkably quick. My experience of diathermy for lupus is limited to four or five cases, but the results with these have been so good that I shall use the method much more in future. The only disadvantage, in the case of lupus involving wide areas of skin, is the length of time that must elapse before a sufficient bed of healthy granulations is formed for the planting of skin-grafts, but considering the uncertainty of the results of simple excision and $X$ ray treatment $I$ do not think this disadvantage is a very serious one. 
I was disappointed that no mention was made during the discussion of the treatment of sarcomata. In February of last year I removed a large sarcoma from the temporal fossa of a man. At its base the tumour had eaten deeply into the bones forming the floor of the fossa, and after scraping away the growth I exposed the whole area of attachment to the action of diathermy. There was no recurrence until about two months ago, when a rapidly-growing tumour appeared in the parotid region, and a fortnight ago I cut down on this, and, finding it entirely confined within the sheath of the masseter muscle, I scraped it out and again diathermised the cavity in which it lay. This case is encouraging because the original site of the sarcoma has remained quite free from growth for nearly a year and a half; and I think that, in view of it, one is justified in giving diathermy a wider trial in the treatment of sarcomata of bone.

There are doubtless many other conditions for which diathermy has been and will be used, and one occurs to me as I write - namely, oriental sore. I have seen it stated that intravenous injections of antimony tartrate act as a specific in this disease. This was not at all my experience when I used the method during the war in Mesopotamia, and I gave it a very wide trial. One sees little of oriental sore in this country, but I shall certainly try the effects of diathermy on it if I have an opportunity.

$$
\text { I am, Sir, yours faithfully, }
$$

R. DAvies-Colley.

Devonshire-place, W., June 22nd, 1922.

** The rerraarks attributed to Mr. Davies-Colley were made by Mr. Philip Turner, to both of whom we express regret for the reporter's slip.-ED. L.

THE NORMAL STOMACH.

\section{To the Editor of THE LANCET.}

Srr,-In the leading article entitled Applied Physics in Medicine in your issue of June 17th is a reference to my contribution to the proceedings at the Congress of Radiology and Physiotherapy. You apparently give me credit for the dissection of the muscle fibres of the stomach which were shown by Mr. G. Jefferson, and which are, of course, his own original work.-I am, Sir, yours faithfully,

Manchester, June 19th, 1922.

A. E. Barclay.

* * We gladly print Dr. Barclay's letter, although the article, read in conjunction with the report of Mr. Jefferson's contribution on p. 1210 of the same issue, was hardly to be misunderstood.-ED. L.

Panel Commitee for the County of London.On June 23rd at a luncheon party, a presentation was made to Dr. Lauriston $\mathrm{E}$. Shaw Treasurer of the Panel Committee since its inception in 1913. The presentation consisted of an oak cabinet, a gramophone, and the Encyclopædia Britannica. Dr. H. J. Cardale, who presided and made the presentation, dwelt on Dr. Shaw's wise economy, persuasive tact, and zeal for the interests of panel practitioners. Dr. Claude Taylor spoke of the unique position held by Dr. Shaw on the Panel Committee. Not being himself a panel practitioner. Dr. Shaw held an entirely disinterested position, and had contributed largely to the radical change in the attitude of the profession towards national health work. In response Dr. Shaw, after cordially thanking the committee on behalf of Mrs. Shaw and himself, recalled the early days of his life as a medical politician. He entirely disagreed with the attitude that medico-political work was less valuable than other forms of medical work. He placed medical activities in the following order of usefulness : (1) discovery and research ; (2) medico-political work, which enabled researches to be made available for the whole community ; (3) work which is restricted to the application of medical benefits to individual patients. The guiding principles of his medico-political life were: (1) the sense of the impossibility for the vast majority of people to give adequate remuneration for the services of their practitioner without some assistance in the direction of insurance; (2) the conviction that the general practitioner must be the first line of defence, and that additional services must be added in coöperation with his service and not substituted for it. These two principles he had found enthroned in the Insurance Act. Mrs. Shaw also replied.

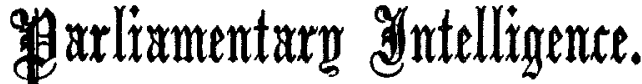

\section{NOTES ON CURRENT TOPICS.}

National Heallh Insurance Bill.

THE Government was defeated on Thursday, June 22nd, $\mathrm{in}$ a Standing Committee of the House of Commons, which was considering the National Insurance Bill. The measure, which was recently introduced by Sir ALFRED MOND (Ministe of Health) proposes as a consequence of one of the recommendations of the Geddes Committee that the total cost of special grants, which amount to $21,800,000$ annually, shall, apart from the Women's Equalisation Fund, which is to be abolished, be charged as from April 1st last to the Benefit Fund of approved societies until December 21st, 1923, when the existing contract with the medical profession terminates. - Mr. CAUTLEY moved an amendment to clause 1 with the object of putting the additional charge on the Central Fund instead of upon the Benefit Fund.- Sir A. Mond said he could not accept the amendment, because the Fund was quite insufficient to pay the money and would be left with a deficiency of $\$ 1,500,000$, the amount required being $£ 3,420,000$.- After discussion, the amendment was carried against the Government by 20 votes to 14 . The debate was adjourned in order to give the Government time to consider the position.

On Tuesday, June 27th, the Committee, on the motion of Sir A. MOND, agreed to a compromise amendment providing that $\$ 900,000$ should be taken from the Central Fund, and the remainder from the Benefit Fund. The Committee stage was concluded and the Bill was ordered to be reported to the House.

\section{HOUSE OF LORDS.}

Monday, June 26Th.

Milk and Dairies Amendment Bill.

The Earl of ONsLow (Parliamentary Secretary to the Ministry of Health) moved the second reading of the Milk and Dairies Amendment Bill which seeks further to postpone the operation of the Milk and Dairies (Consolidation) Act, 1915, and the Milk and Dairies (Scotland) Act, 1914, to make further provision with regard to the sale of milk and for purposes connected therewith. He said that the 1915 measure was not being " scrapped " as had been supposed in some quarters. It was merely being postponed for a period of three years because at the present time it was impossible to face the expenditure that would be entailed if it was brought into operation. The 1915 Act imposed new duties on county councils and a Departmental Committee which was appointed in 1920 to investigate the cost of working the measure reported that it would require a sum of $£ 704,000$ per annum. The Ministry of Health also went into the question of cost and arrived at a figure which was a trifle less. But in addition to that large sum the compensation paid under the measure would amount to $£ 150,000$ a year, so that a total sum of about $£ 850,000$ per annum would be necessary if the 1915 Act were put into operation. That figure would tend to increase. The present Bill sought to do three things. First of all, it was designed to protect the consumer in respect of the sale of milk which was injurious to health; secondly, it would, he hoped, provide milk at a cheap rate free from bacterial contamination ; and thirdly, it prohibited the sale of milk from cows which were suffering from tuberculosis of the udder.

Lord STRACHIE moved the rejection of the Bill on the ground that it was better to postpone legislation until it was possible to bring in a thoroughly good Bill.

Lord DYNEvor supported the Bill.

After some discussion Lord STRACHIE withdrew his motion for rejection and the Bill was read a second time.

\section{HOUSE OF COMMONS.}

WEDNESDAY, JUNE $21 \mathrm{sT}$.

Compensation for Medical Officers in Territorial Army.

Lieut.-Colonel Fremantue asked the Secretary of State for War what compensation was proposed for those D.A.D.M.S.'s of the Territorial Army whose appointments, originally made for a period of four years, had been prematurely terminated at the expiration of two years or less.Lieut.-Colonel Sir R. A. SANDERS (Under Secretary to the War Office) replied : Those Deputy Assistant Directors of Medical Services of the Territorial Army whose appointments, originally made for a period of four years, have been prematurely terminated from March 1st last, will be given as compensation for the professional loss involved in the premature termination of their army contracts, a sum representing one-third of what they would have received in pay and allowances if they had been allowed to complete the term of their appointments. 